immense amount of detailed and accurate work devoted to stratigraphical geology and palæontology by the geologists of large oil companies. As a result, much information, widely scattered in the literature and in private reports, is available for an adequate interpretation of the larger problems of regional and historical geology. Synthesis has lagged behind, and the author of this admirable book has rendered valuable service not only to the geologists of the State, but also to a wider circle, by furnishing a simple, well written and beautifully illustrated account of the present status of geological investigation in California.

The first four chapters deal with geological provinces, structural problems, and pre-Mesozoic and Triassic rocks, and chapters are then devoted to each of the succeeding systems in turn, postJurassic events receiving most attention. As chief geologist to an important oil company, the author writes with particular authority on the Miocene beds and the diastrophism which they reveal. The book should have a special value in stimulating research, since it directs attention to the many complex problems that remain to be solved before the full history of the coast ranges and other parts of California can be written.

In addition to a detailed index of authors and subjects, there is a useful appendix of geographical names and a locality index map; this feature might well be adopted in all similar works since it saves the unfamiliar reader much mental friction. The illustrations effectively portray a wide range of phenomena.

\section{On a New Chemical Theory and Researches on} Salicylic Acid. Papers by Archibald Scott Couper (1858). (Alembic Club Reprints, No. 21.) Pp. 45. (Edinburgh : Oliver and Boyd ; London : Gurney and Jackson, 1933.) $2 s .6 d$.

THE latest of the Alembic Club reprints gives us the papers of Archibald Scott Couper who, as is now recognised, shares equally with Kekulé the credit for enunciating the theoretical conception of the linking of carbon atoms in the molecules of organic compounds. Few conceptions have been more fruitful of results or had greater influence on the development of chemistry, and it is most desirable that the part played by Couper should be established beyond doubt. The studies of Anschütz published in 1909 have done much to make clear his achievements, showing in particular that there was a delay in the presentation of his first paper to the Paris Academy owing to the dilatory action of Wurtz. Following the sympathetic biography of Anschütz, the Scottish chemists combined in 1931 to place a memorial plaque at Townhead, Kirkintilloch, where Couper was born in 1831, the full circumstances being placed on record in the Journal of the Society of Chemical Industry, vol. 50.

The present reprint gives the short note on "A New Chemical Theory" presented to the Academy by M. Dumas, and the full English paper supplemented by certain additions from the later French version. Both the French and English versions of the paper "Researches on Salicylic Acid" are given, the former being apparently the earlier, as Couper made the change from $\mathrm{C}=6$ to $\mathrm{C}=12$ between their respective dates of publication.

No student of organic chemistry should fail to read these papers.

An Introduction to Thermodynamics for Chemists.

By Dr. D. Johnston Martin. Pp. vii +343.

(London: Edward Arnold and Co., 1933.) 16s. net.

THE object of the author of this textbook is to provide a work of a less advanced and detailed nature than the classic volume of Lewis and Randall, and at the same time to clarify certain fundamental principles with the view of making the subject one of real utility to the practical chemist. Thus, since most measurements refer to reactions at constant pressure, the advantage is urged of employing the criterion of zero free energy change at constant temperature, instead of zero maximum work of a process at constant volume and temperature, since the former is true of any reaction whatsoever.

A clear differentiation between free energy and maximum work is emphasised, and special attention is given to a proper appreciation of the concept of entropy. The rest of the text, apart from developing the laws of thermodynamics, deals with the application of thermodynamic principles to continuity of state, homogeneous systems, dilute solutions, electrochemistry of dilute solutions, the activity treatment of solutions, strong electrolytes, chemical affinity and heterogeneous systems. All these are well illustrated by tabulated data for an extensive range of substances and reactions.

The book should fill the needs of a wide circle of students and investigators; no advanced mathematics is introduced, printing and production are of a high order, and there is a really efficient author and subject index.

N. M. B.

Commonwealth Bureau of Census and Statistics, Canberra. Official Year Book of the Commonwealth of Australia. No. 26, 1933 . Prepared by E. T. McPhee. Pp. xxxii +942 . (Canberra : Government Printer, 1934.) $5 s$.

THIs useful year-book may almost be regarded as a model of arrangement and condensation. The need for economy still restricts its growth and precludes the inclusion of the special articles for which earlier issues were noted. The essential statistical matter, however, has not suffered curtailment. A special index refers to longer articles in former issues. In this issue the vital statistics of the 1933 census have been included and analysed. Agricultural, pastoral and mining activities are fully treated and made more valuable by the inclusion of many comparative statistics for other countries. Full attention is paid to labour, wages and public finance, while an appendix gives the history of the financial crisis in Australia. A list of useful books on Australia is added. 